\title{
ANALISIS CUANTITATIVO Y CUALITATIVO DE HONGOS ZOOSPORICOS DE LA LAGUNA VITEL Y TRIBUTARIOS (PROV. BUENOS AIRES, ARGENTINA)
}

\author{
(Quantitative and qualitative analysis of zoosporic fungi from Vitel lagoon) \\ and tributaries (Prov. Buenos Aires, Argentina)
}

\author{
Mónica M. Steciow \\ Instituto de Botánica Spegazzini, $53 \mathrm{~N}^{\circ}$ 477. (1900) \\ La Plata. Bs.As. Argentina. CONICET.
}

Palabras clave: Hongos zoospóricos, Oomycetes, Chytridiomycetes, Argentina.

Key words: Zoosporic fungi, Oomycetes, Chytridiomycetes, Argentina.

\section{RESUMEN}

Drante el año 1993-9t, mediante el análisis mensual de muestras de agua y de materia orgánica flotante, se realizó un estudio cuanti-cualitativo de los hongos zoospóricos (Oomycetes, Chytridiomycetes) presentes en la Laguna Vitel y sus tributarios (Chascomis, de la prov. de Buenos Aires). Utilizando anzuelos vegetales (semillas de Cannabis saiva y Brassica sp.), se aislaron 31 especies de hongos zoospóricos, de las cuales 16 son citadas por primera vez para Argentina. El análisis cuantitativo de sus propágulos totales por litro, determinó un mayor contenido en los periodos estacionales de otoño y primavera.

\section{INTRODUCCION}

Los hongos acuáticos forman parte de la biota de los arroyos y cuerpos de agua dulce, constituyendo un grupo ubicuo y abundante, que juega un significativo papel en la complejidad de las interacciones biológicas en las aguas terrestres, ya sea como saprobios en la degradación de sustratos complejos o como parásitos de algas, peces y de otros hongos acuáticos (Johnson, 1956; Sparrow, 1960; Fuller \& Jaworski, 1987).

Motivados por la escasa información que se tiene en Argentina y en Sudamérica, acerca de la presencia y distribución de las especies de hongos zoospóricos en los distintos cuerpos de agua dulce, se tomó como punto de partida, no solo el análisis cualitativo sino el cuantitativo
SUMMARY

Within 1993-1994, using a monthly analysis of water samples and floating organic matter, a quantiqualitative study of zoosporic fungi (Oomycetes, Chytridiomycetes) present in Vitel Lagoon and its tributaries (Chascomus, province of Buenos Aires) was made. By using vegetal baits (Camnabis sativa and Brassica sp. Seeds), 31 species of zoosporic fungi were isolated, 16 of which being reported for the first time for Argentina.

For the quantitative analysis it was estimated the propagule numbers per litre by spreading freshwater aliquots in solid medium, having found the greatest number in spring and autumn.

en uno de estos ambientes.

Para ello, se comenzaron a realizar muestreos mensuales en el Partido de Chascomús, en el ecosistema acuático comprendido por el arroyo Vitel Sur, Laguna Vitel y tributarios (Prov. de Buenos Aires).

Es interesante destacar que entre los antecedentes bibliográficos sobre estudios limnológicos desarrollados en la laguna Vitel, sólo figuran los de Olivier (1961) y los de Dangavs \& Merlo (1991), con una caracterización geomorfológica completa de la laguna y su cuenca de drenaje. Asimismo, se realizaron algunas investigaciones del fitoplancton (Guarrera, 1968; Echenique \& Arenas, 1994), habiéndose realizado hasta el momento pocos estudios micológicos en esta laguna y en sus arroyos tributarios (Steciow, 1996, 1997). 
En la presente contribución se destacan principalmente los estudios cuantitativos más que los cualitativos de las especies de Oomycetes y Chytridiomycetes de este ambiente acuático, sin fines comparativos entre los sitios de muestreo.

\section{MATERIALES Y METODOS}

\section{1.- Descripción del área de muestreo:}

La laguna Vitel, está a una distancia de $8 \mathrm{Km}$ de la ciudad cabecera del partido de Chascomús (Prov. de Buenos Aires, Argentina) y toda la región está comprendida dentro de la llanura pampeana. La laguna Vitel es el primer eslabón del sistema de Lagunas Encadenadas de Chascomús, las que se hallan intercomunicadas por cortos arroyos. Se encuentra situada entre las coordenadas $35^{\circ} 30^{\prime} 49^{\prime \prime}$ y $35^{\circ} 32^{\prime} 47^{\prime \prime}$ de latitud sur y $58^{\circ} 04^{\prime} 30^{\prime \prime}$ y $58^{\circ}$ 09' 10" de longitud Oeste.

El lecho de la laguna es bastante regular, sin accidentes notables; el fondo es plano, y presenta bordes elevados, constituídos por la costa barrancosa.

\section{2.- Sitios de muestreo:}

Se tomaron muestras de los siguientes sitios:

- arroyo Vitel Sur: de 2,4 Km de largo, emisario que la comunica con la laguna de Chascomús y en cuyas nacientes, para elevar el espejo de agua se construyó en 1956 un dique nivelador.

- laguna Vitcl.

- canal de descarga de deshechos de la planta industrial Gándara.

Los muestros se relizaron mensualmente a partir de julio/93, por el término de 1 año.

\section{3.- Procesamiento de las muestras:}

3.1.- Análisis cualitativo:

3.1.1.- Colección: Las especies se obtuvieron por extracción mensual de: 1) Muestras de agua, 2) Matcria orgánica flotante.

En general las muestras de agua fueron obtenidas de la superficie y hasta una profundidad no mayor de 30$40 \mathrm{~cm}$. Las muestras de cada sector $(5$ por sector, con frascos de 1 litro) se mezclaron y distribuyeron e $(15 \mathrm{ml})$ en 20 placas de Petri. Tambićn la materia orgánica particulada se sembró también en 20 placas de Petri a las que se adicionaron mitades de semillas de cáñamo y/o Brassica sp. (nabo, rabanito), utilizados como sustratos favorables para el crecimiento de estos hongos zoospóricos.

Del mismo modo se cebaron los trozos de tallos, hojas, y frutos (materia orgánica flotante) que fueron colocados con $10 \mathrm{ml}$ de agua estériles en 20 placas de Pctri.
3.1.2.- Aislamiento y conservación de las cepas en cultivos puros.

Se realizó con la ayuda de pinzas, a partir de hifas, yemas, oogonios o de zoosporangios colocados en agar harina de maiz. Este medio también es empleado para el mantenimiento de las especies encontradas.

\section{2.- Análisis cuantitativo:}

3.2.1.- Para el cálculo del contenido de propágulos por litro de agua solo se consideró las muestras efectuadas en el arroyo Vitel sur.

La metodología empleada es la propuesta por Willoughby (1962), y continuada por Willoughby \& Collins (1966); Ji \& Dayal (1966); Hallett \& Dick (1981). Consiste en colocar alícuotas de muestras de agua $(5 \mathrm{ml})$, en placas de Petri que contienen $10 \mathrm{ml}$ de agar harina de maiz, justo antes de solidificar.

Una vez que el agar ha solidificado, se separaron 8 sectores triangulares de agar, del mismo tamaño por cada placa de Petri, los que se colocaron en agua destilada estéril, a temperatura ambiente, por el término de 7 días. Se emplearon 5 placas por cada muestra de agua, resultando un total de 40 sectores triangulares en cada estimación.

Luego de este período de incubación, se observaron los sectores para detectar el crecimiento hifal, contándose como"sectores positivos" a aquellos que mostraron el crecimiento de éstas.

Las colonias fucron determinadas por crecimiento de las hifas sobre semillas de Brassica sp. en cultivos de agua.

De esta forma se estimó el contenido de Saprolegniales en muestras de agua, en términos de propágulos por litro, contando el número de sectores positivos. Tal estimación se corrigió calculando aquellos sectores esperados que contengan más de un propágulo por sector, por empleo de la distribución de Poisson.

\subsection{2.- Cálculo del contenido de propágulos por litro de agua (Solo en Arroyo Vitel Sur)}

Con la metodología empleada se realizó la estimación del contenido de Oomycetes expresado en propágulos por litro, contando el número de sectores positivos.

Como la cantidad de agua colocada en las 5 placas de Petri (empleadas para el estudio en cada zonà) fue de un total de $25 \mathrm{ml}$, de modo que la estimación del número de propágulos por litro fue calculada multiplicando el número de seclores positivos por 40.

Este primer cálculo se realizó partiendo del criterio referido a que cada sector de agar que permite el crecimiento de una especie, perteneciente a los Oomycetes, 
tenía originalmente un solo propágulo (zoospora). Por empleo de la distribución de Poisson, se calculó el número de sectores esperados que contenían más de un propágulo por sector. Así por ejemplo, si 50 propágulos se distribuyen al azar en 100 sectores (media real $=0,5$ ), la distribución esperada de acuerdo a Poisson, sería de 61 sectores sin propágulos, 30 sectores conteniendo 1 propágulo, 7 sectores que contienen 2 propágulos y 2 sectores que contienen 3 propágulos. El número de sectores positivos registrados corresponde a: $30+7+2=39$, y la media observada: 39 / $100=0,39$ comparada con la media real de 0,5 .

Para realizar estas correcciones se calcularon las medias observadas de sectores positivos correspondientes a las medias reales, estimadas para valores desde 0,1 a 1 propágulo por sector (Fig. 1).

De tal forma se estimó para cada mes, el número de propágulos por litro, a partir del muestreo correspondiente a julio/93.

La corrección del cálculo de los propágulos por litro se realizó de la siguiente manera:

Por ejemplo, si el número de sectores positivos observados fue igual a 5 , por lo que:

-Volumen de muestra de agua: $25 \mathrm{ml}$ (5 cajas x 5 $\mathrm{ml})$.

$-\mathrm{N}^{\circ}$ de sectores triangulares: 40 (5 cajas $\times 8$ ).

$-\mathrm{N}^{\circ}$ de sectores positivos: 5 .

-Estimación incorrecta: $5 \times 40=200$ propágulos/ litro.

-Media observada de sectores positivos: $5 / 40=$ 0,12 .

-Media real correspondiente a la media observada de $0,12=0,16$

$-\mathrm{N}^{\circ}$ correcto de propágulos: $0,16 \times 40=6,4$.

-Estimación correcta: $6,4 \times 40=256$ propágulos/ litro.

\section{RESULTADOS}

\section{1.- Análisis cualitativo}

Durante el estudio llevado a cabo en la Laguna Vitel, Arroyo Vitel Sur y Canal Gándara se hallaron especies pertenecientes a los Ordenes Saprolegniales, Lagenidiales, Peronosporales y Monoblepharidales (Cl. Oomycetes) y Chytridiales (Cl. Chytridiomycetes). Estas fueron obtenidas a partir de las mucstras de agua y de materia orgánica flotante, las que al cabo de 1 semana, mostraron el crecimiento miceliar de las especies sobre las semillas utilizadas como sustrato para la fijación de las zoosporas (Tabla 1).

Tabla 1. Presencia de especies en muestras de agua y de materia orgánica en los 3 sectores de muestreo.

ESPECIES

$\begin{array}{cc}\text { MUESTRAS } & \text { MUESTRAS } \\ \text { DE AGUA } & \text { DE MATERIA } \\ & \text { ORGANICA }\end{array}$

Achlya. apiculata

A. cambrica

A. caroliniana*

A. conspicua

A. flagellata

$\mathbf{x}$

$\mathbf{x}$

$\mathbf{X}$

$\mathbf{X}$

$\mathbf{X}$

A. inflata

A. oblongata var.oblongata

A. prolifera

Achlya sp.1

Achlya sp. 2

$\mathbf{x}$

$\mathbf{X}$

Aphanomyces irregulare* $\mathrm{X}$

Aphanomyces laevis* $\quad \mathrm{X}$

Aphanomyces sp1 $\quad \mathrm{X}$

Catenaria anguillulae* $\mathbf{X}$

Dictyuchus anomalus* $\mathbf{X}$

Dictyuchus carpophorus*

Dictyuchus monosporus $\mathrm{X}$

Lagenidium sp

Monoblepharella mexicana* $\mathbf{X}$

Olpidiopsis achlyae*

Olpidiopsis saprolegniae

var. suprolegnia

Pythiogeton utriforme * $\mathrm{X}$

Pythium aphanidermatum $\mathrm{X}$

Pythium sp1 X

Rhizophydium carpophilum * $\mathrm{X}$

Rozellopsis simulans* $\quad \mathbf{X}$

Saprolegnia ferax* X

Saprolegnia glomerata* $\quad \mathrm{X}$

Saprolegnia litoralis* $\quad \mathbf{X}$

Saprolegnia aff. uliginosa ${ }^{*} \mathrm{X}$

Zoophagus insidans*

$\mathbf{X}$

$\mathbf{X}$

$\mathbf{X}$

$\mathbf{X}$

$\mathbf{X}$

$\mathbf{X}$

$\mathbf{X}$

$\mathbf{X}$

$\mathbf{X}$

$\mathbf{X}$

$\mathbf{X}$

$\mathbf{X}$

$\mathbf{X}$

$\mathbf{X}$

$\mathbf{X}$

$\mathbf{X}$
$\mathbf{X}$

$\mathbf{X}$

Las especies señaladas por un $\left(^{*}\right)$ fueron encontradas por primera vez en Argentina.

Análisis cuantitativo. Hasta el momento, de los datos obtenidos desde julio/93-julio/94, el número de propágulos por litro alcanzó valores superiores en los meses de primavera, con una cantidad considerable en septiembre/ 93 con 1120 propágulos/litro. En cambio, en julio/93 y encro-febrero/94, los valores fueron mínimos (160 propágulos/litro ). En los meses de otoño/94, se visualizó un aumento en dicho número, alcanzando valores de hasta 
736 propágulos/litro en el mes de abril/94. (Tabla 2).

Tabla 2. Número de sectores positivos y estimación de propágulos/litro según mes en Arroyo Vitel Sur

$\begin{array}{lrr}\text { MES } & \begin{array}{r}N^{\circ} \text { de sectores } \\ \text { positivos }\end{array} & \begin{array}{r}\mathbf{N}^{\circ} \text { de propágulos/ } \\ \text { litro }\end{array} \\ \text { Julio/93 } & 3 & 160 \\ \text { Agosto/93 } & 5 & 256 \\ \text { Septiembre/93 } & 22 & 1120 \\ \text { Octubre/93 } & 9 & 384 \\ \text { Noviembre/93 } & 11 & 560 \\ \text { Diciembre/93 } & 11 & 560 \\ \text { Enero/94 } & 3 & 160 \\ \text { Febrero/94 } & 3 & 160 \\ \text { Marzo/94 } & 7 & 320 \\ \text { Abril/94 } & 15 & 736 \\ \text { Mayo/94 } & 12 & 576 \\ \text { Junio/94 } & 5 & 256 \\ \text { Julio/94 } & 3 & 160\end{array}$

\section{DISCUSION Y CONCLUSIONES}

Se analizó la micota de hongos zoospóricos presente en el ambiente integrado fundamental mente por la Laguna Vitel y el Arroyo Vitel Sur. Durante cl estudio llevado a cabo se encontraron 25 especies de hongos zoospóricos, las cuales son saprotrofas y algunas de ellas parásitas de peces, crustáceos y otras especies de hongos filamentosos.

De estas especies, 16 constituyen primera cita para la Argentina: Achlya caroliniana, Aphanomyces irregulare, Aphanomyces laevis, Dicty'uchus anomalus, D. carpophorus, Saprolegnia ferax, S. glomerata, $S$. litoralis, $S$. aff. uliginosa ; Olpidiopsis achlyae ; Pythiogeton utriforme, y Zoophagus insidans; Monoblepharella mexicana. (Monoblepharidales); Catenaria anguillulae, Rhizoplydium carpophilum y Rozellopsis simulans.

Algunas de cstas especies han sido halladas antcriormente en ambientes de la prov. de Buenos Aires, con características muy diferentes a las del Arroyo Vitel Sur y Laguna Vitel, como el integrado por el Río Santiago y afluentes (Steciow, 1988; Steciow, 1993). particularmente afectado por crudo de petrólco y derivados de éste (aceites y combustibles).

Achlya inflata y $A$. flagellata fueron halladas previamente en otros cuerpos de agua de la Argentina (Beroqui, 1970).

Las especies: Achlya caroliniana, Aphanomyces irregulare, Saprolegnia glomerata, Pythiogeton utriforme, Zoophagus insidans y Olpidiopsis achlyae, fueron descritas para Argentina en otro trabajo anterior (Steciow, 1996).

Del mismo modo Saprolegnia litoralis, Rozellopsis simulans), Catenaria anguillulae, Lagenidium destruens, que fue encontrada parasitando hifas de Dictyuchus monosporus, y Rhizophydium carpophilum, parasitando oogonios de $A$ chlya sp. ( los que no alcanzan a desarrollar oosferas en su interior), constituyen nuevos hallazgos para nuestro país, cuyas descripciones forman parte de otra contribución (Steciow, 1997).

Monoblepharella mexicana, fue abundante sobre las semillas utilizadas como cebos en muestras tomadas en el Canal Gándara y arroyo Vitel Sur, por lo que se trataría de una especic "resistente o tolerante" a la falta de oxígeno y/o a la presencia de mayor concentración de detcrminados componentes, entre ellos sales en solución. Forma pequeñas pústulas blancas sobre los sustratos sumergidos sobre los cuales es encontrada, desarrollando un micelio delgado, de escaso crecimiento, muy vacuolado y ramificado, con porciones ensanchadas y con abundantes zoosporangios. Del género Monoblepharella se conocen 5 especies, obtenidas a partir de suelos tropicales y subtropicales del hemisferio occidental (Karling, 1981; Fuller \& Jaworski, 1987).

- Pythium aphanidermatum, caracterizada por la formación de numerosos zoosporangios lobulados, fue muy abundante y desarrolló numerosos oogonios, en muestras de agua incorporadas en corn meal agar.

Zoophagus insidans es otra especie hallada en Canal Gándara, y tambićn en arroyo Vitel Sur, y obtenida a partir de materia orgánica cebada con semillas de Brassica sp., dejadas en condiciones con bajos valores de oxígeno, por un período supcrior a 15-20 días. Resulta interesante destacar que este hongo zoospórico es capaz de capturar rotíferos, con los cuales se lo encontró asociado (Steciow, 1996). Es una especie citada para ambientes con alto contenido en desperdicios orgánicos (Fuller \& Jaworski, 1987).

Rozellopsis simulans, causa ligera hipertrofia y septación de las hifas del hospedante (Achlya spp). Esta especie ha sido citada como parásita de Achlya polyandra, $A$. racemosa, $A$. flagellata (Karling, 1981).

Catenaria anguillulae, es parásita de nematodes, y saprotrofa sobre restos orgánicos vegetales y agar nutritivo. El talo está compuesto de hifas septadas, ramificadas, con rizoides.

Los resultados del número de propágulos/l muestran una relación con el estudio llevado a cabo en Río Santiago (Pdo. Ensenada, Bs.As.), a pesar de ser un ambiente muy modificado en sus condiciones naturales ( Steciow, 1996), y con el trabajo de Hallett \& Dick (1981), en los que se encontraron picos de máximo número de propágulos en los meses de primavera. 
12: 509-517.

Figura 1. Corrección para inoculaciones múltiples empleadas en la estimación de Oomycetes.

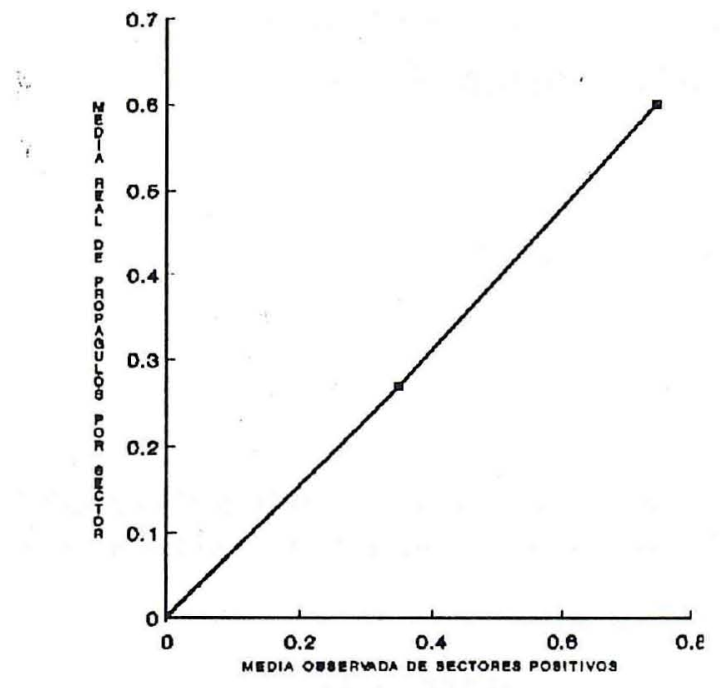

\section{AGRADECIMIENTOS}

Deseo expresar mi agradecimiento a la Dra Angćlica M. Arambarri por los conscjos durante la realización de este trabajo y al CONICET por el subsidio otorgado para el financiamiento del estudio de los hongos acuáticos.

\section{REFERENCIAS}

Beroqui de Martinez, M. E. (1970). Contribución al estudio de los Plyycomycetes acuáticos de la República Argentina. Bol. Soc. Argent. Bot. 13: 109-124.

Dangavs, N. V.\& Merlo, D. O. (1991). Contribución a la geolimnologia de la Laguna Vitel. Partido de Chaseomús. Provineia de Buenos Aires. Informe de la CIC (Bs. As.). Inédito.

Echenique, R. O. \& Arenas, P. M. (1994). Fitoplaneton de la Laguna Vitel, Argentina. I. Gayana Bot. 51:89-104.

Fuller, M. S. \& Jaworski, A. (1987). Zoosporic Fungi in Teaching and Research. Southearsten Publishing Corp.

Guarrera, S. A., Cabrera, S. M., Lopez, F. \& Tell, G.(1968). Fitoplaneton de las aguas superficiales de la Prov. de Buenos Aires I. Area de la Pampa Deprimida. Rev. Mlus. La Plata (Sece. Bot.) 10: 22.3-331

IIallett, I. C.. \& Dick, M. W.(1981). Seasonal and diumal fluctuations of Oomy'cete propagule numbers in the free water of a freshwaler lake. I. Eeol. 69: 671-692.

Ji, T. \& Dayal, R.(1966). The oceurrence and distribution of reproductive spores of Saprolegniales in certain ponds of Varanasi. Nival Hedwigia
Johnson, T. W.,Jr. (1956). The genus Achlya: Morphology and Taxonomy. Univ. Michigan Press, Ann. Arbor, Michigan. XV+180pp.

Karling, J. S. (1977). Chỵtridiomycetarum Iconographia. J.Cramer.

(1981). Predominantly holocarpic and eucarpic simple flagellate Phycomycetes. J. Cramer.

Olivier, R. O.(1961). Estudios limnológicos en la Laguna Vitel (Pdo. de Chascomus, B. A. Argentina). AGRO 3: 1-128.

Sparrow, F. K., Jr. (1960). Aquatic Phyconycetes. 2nd. ed. Ann. Arbor, Univ. Michigan Press. Michigan. 1187 pp.

Steciow, M. M. (1988). Algunos Oomycetes de ambientes acuáticos de la provincia de Buenos Aires. Bol. Soc. Argent. Bot. 25:333-346.

- (1993). Presencia de Saprolegniales (Mastigomycotina) en Rio Santiago y afluentes. Bol. Soc. Argent. Bot. 29: 211-217.

(1996). Hongos acuaticos zoospóricos (Oomycetes, Mastigomy cotina) en laguna Vitel y tributarios (Buenos Aires, Argentina). Bol. Soc. Argent. Bot. 32: 67-73.

.(1996). Estudio cuantitativo de los Oomy'cetes de Rio Santiago y afluentes (Buenos Aires, Argentina). Rev. Asoc. Cs. Nat. del Litoral 27:119-126.

(1997). Fongos acuáticos zoospóricos (Mastigomy'cotina) en laguna Vitel y tributarios (Buenos Aires, Argentina). Darwiniana (En prensa).

Willough by, L. G. (1962). The occurrence and distribution of reproductive spores of Saprolegniales in fresh water. J. Ecol. 50:733-759.

Willoughby, I. G. \& Collins, V. G. (1966). A study of the distribution of fungal spores and bacteria in Blelham Tarn and its associated streams. Nova Hedwigia 12:150-171 